\title{
Physicochemical properties of enzymatically produced palm-oil-based cocoa butter substitute
}

(CBS) with cocoa butter mixture

\begin{abstract}
Ternary-blend of palm mid-fraction/palm kernel oil/palm stearin shows comparable palmitic $(\mathrm{P})$, oleic $(\mathrm{O})$, and POP compositions to cocoa butter $(\mathrm{CB})$ which is selected to produce cocoa butter substitute (CBS) using enzymatic interesterification. This study aims to investigate physicochemical properties of CBS and compatibility of CBS/CB. Fatty acid, triacylglycerol, melting profile, solid fat content (SFC), polymorphism, and crystal morphology are determined using GC, HPLC, DSC, pNMR, XRD, and PLM. Ternary-blend and commercial stearic/oleic acids are mixed to produce blend ( $80 \%$ ternary-blend $/ 15 \%$ stearic $/ 5 \%$ oleic) with three major fatty acids composition comparable to $\mathrm{CB}$. Interesterified blend under optimized conditions of $4 \%$ lipase $(\mathrm{w} / \mathrm{w})$, incubation time of $6 \mathrm{~h}$ at $60^{\circ} \mathrm{C}$ shows a melting endotherm at $33.5^{\circ} \mathrm{C}$, similar to $\mathrm{CB}$. The composition of triacylglycerols (POSt and StOSt) of interesterified blend is significantly $(\mathrm{P}<0.05)$ increased compared to non-interesterified blend. SFC and polymorphism of interesterified fat are different from CB at $24{ }^{\circ} \mathrm{C}$. Subsequently, the CBS (interesterified blend) is added into $\mathrm{CB}$ at varying concentrations (w/w). A total of $5-20 \%$ of $\mathrm{CBS} / \mathrm{CB}$ shows similar melting behavior and polymorphism to $\mathrm{CB}$. A desirable monotectic effect is observed at $15-25^{\circ} \mathrm{C}$ for these blends. Therefore, interesterified blend is potentially used as CBS to be added up to $20 \%$ with CB for chocolate production.
\end{abstract}

Keyword: Cocoa butter substitutes; Compatibility; Interesterification; Lipase; Microstructure 